\title{
Comparative analysis of the effectiveness of the conceptual rainfall-runoff hydrological models on the selected rivers in Odra and Vistula basins
}

\author{
Robert Mańko ${ }^{1}$, and Norbert Laskowski ${ }^{1, *}$ \\ ${ }^{1}$ West Pomeranian University of Technology in Szczecin, Department of Water Engineering, Szczecin, Poland
}

\begin{abstract}
Identification of physical processes occurred in the watershed is one of the main tasks in hydrology. Currently the most efficient hydrological processes describing and forecasting tool are mathematical models. They can be defined as a mathematical description of relations between specified attributes of analysed object. It can be presented by: graphs, arrays, equations describing functioning of the object etc. With reference to watershed a mathematical model is commonly defined as a mathematical and logical relations, which evaluate quantitative dependencies between runoff characteristics and factors, which create it. Many rainfall-runoff linear reservoirs conceptual models have been developed over the years. The comparison of effectiveness of Single Linear Reservoir model, Nash model, Diskin model and Wackermann model is presented in this article.
\end{abstract}

\section{Introduction}

\subsection{Description of the phenomenon}

A watershed is a fundamental research facility in hydrology. Considering it as a system, all forms of water inflow into the watershed, such as: precipitation, surface runoff, interflows coming from beyond the analysed area are understood as input variables. Output variables depend on the purpose of the research, for instance: transformation of rainfall into runoff, determination of effective rainfall, river sediment calculations, surface runoff water loss etc. It is essential to distinct the system components in the research unit and to define its surroundings to treat the research unit as a system. This selection depends on problem we consider. For example, considering watershed as a system, we must delimit in its environment relations with other elements, which have an impact on analysed process, for instance surface runoff. [1] Depending on the purpose of the research, some objects may be included either in the system or in the environment. Areas, where environment affect the system, are called system input, and areas where the system interacts with the environment - the system output. However, the terms input and output commonly refer to input and output signals. [2] Final internal structure of the system and its effect on environment is determined by object attributes reliance. System analyse is used in natural systems, called real systems and simplified system models. The natural systems include all processes, which occur in research unit, while the simplified systems include only part of them. Due to complexity of phenomena occurring in nature and relations between them, these are the simplified models that have more frequent application. Rainfall-runoff models: Single Linear Reservoir Model, Nash model, Diskin model and Wackermann model, are classified, as simplified models. Idea concept of the model is presented in the figure 1 [1].

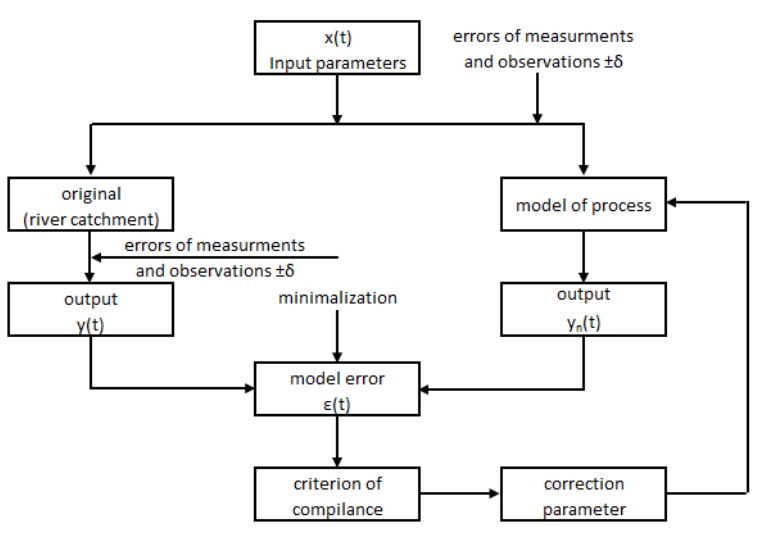

Fig. 1. Idea concept of the mathematical model in hydrology (by. Kovara 1984) [1]

In order to create foundations on rational methodology of hydrology models application, there is a need for systematizing researches in branch of mathematical modelling of systems. When creating rational methodology for concentrated linear system is impossible, then attempts of creating it in more complicated models seem useless. 


\subsection{Research facility characteristics}

The following river watersheds were adopted as research facility:

- Czerwona Woda (Odra river basin),

- Piotrkówka (Odra river basin),

- Soła (Vistula river basin),

- Żebrówka (Vistula river basin),

- Pasłęka (Vistula river basin)

\subsubsection{Czerwona Woda}

Czerwona Woda river is $22 \mathrm{~km}$ long and is Nysa Łużycka right confluent. The river flow begins at the base of Izerskie Mountains. Czerwona Woda catchment area is approx. $130 \mathrm{~km}^{2}$. Rain data has been gathered in Zgorzelec precipitation station, placed in Czerwona Woda estuary.

\subsubsection{Piotrkówka}

Piotrkówka river is $31 \mathrm{~km}$ long and is Olza river confluent. Zebrzydowice profile was adopted in calculation, where Piotrówka is $12.4 \mathrm{~km}$. distant from the estuary. Watershed area in the profile is $115 \mathrm{~km}^{2}$. Rain data has been gathered in Jastrzębie Zdrój precipitation station, which is located approx. $10 \mathrm{~km}$. away from Zebrzydowice.

\subsubsection{Soła}

Soła is a foothill nature river, located in the south of Poland. Total long of Soła is almost $90 \mathrm{~km}$, where in Rajcza profile catchment area amounts $254 \mathrm{~km}^{2}$. The precipitation height was measured in Piekło village.

\subsection{4 Żebrówka}

Żebrówka is a $23 \mathrm{~km}$ long river in Silesia in Poland. It takes its origin in Siadcza village, and ends its run in Krztynia. The watershed area in Bonowice profile amounts $129 \mathrm{~km}^{2}$. The precipitation data was registered in Ołudza.

\subsubsection{Pasłęka}

Pasłęka is a $211 \mathrm{~km}$ long river, located in north-east part if Poland. Volumes of rainfall and runoff were measured in $145.7 \mathrm{~km}$ of river run in Tomaryny village (catchment area amounts $183 \mathrm{~km}^{2}$ ).

\subsection{Effective rainfall and its transformation process}

The effective rainfall is the part of the precipitation, which forms high waters of the watercourse in the form of surface runoff. The remaining part of the rainfall is the loss, caused by interception, evapotranspiration, infiltration or filling soils depressions. The quantitative variability of the mentioned components is dependent on constant and changeable characteristics of watershed and hydrometeorological conditions. Due to the fact that the surface runoff usually takes place during rainfall, when the conditions are not conducive to the evaporation process, losses caused by evaporation can be omitted. Because of its small amount, the applied simplification won't result in effective catchment supply model flagrant mistake. The most important factor of surface runoff forming process is infiltration, what is presented in the figure 2 [1].

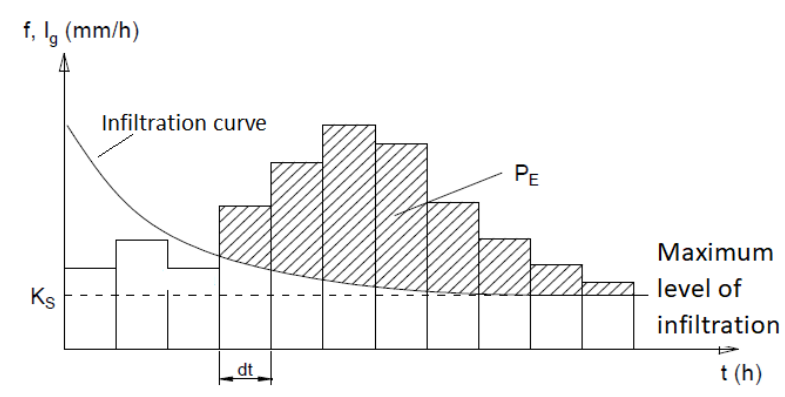

Fig. 2. The definition of trajectory of effective rainfall $P_{E}(t)$ [1].

In first three periods of time, infiltration capability of soil exceeds water supply to the ground, therefore the effective rainfall is zero. The forming of effective rainfall begins just in fourth period, when precipitation exceeds soil infiltration capability. As can see, amount of effective rainfall is significantly smaller than total rainfall, moreover its participation in total rainfall is changing over time. The immediate runoff coefficient method may be used to set down the effective precipitation. $[3,4]$.

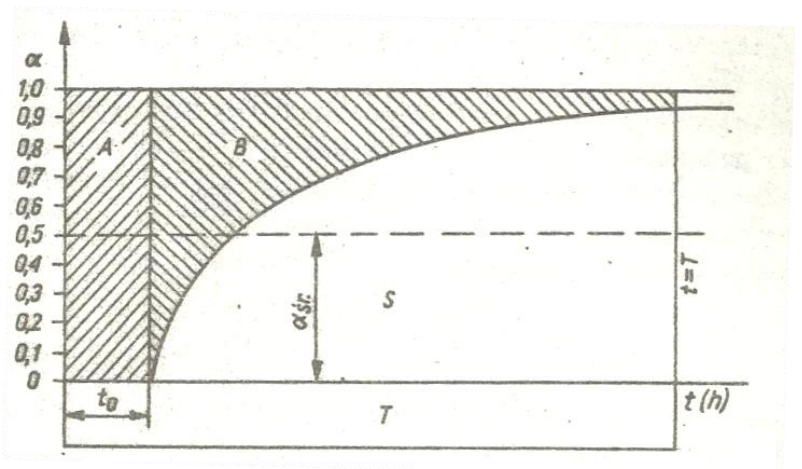

Fig. 3. The trajectory of immediate runoff coefficient $\left(\alpha_{p}\right)$ [3].

As presented in the figure 3, the first period of rainfall determine runoff coefficient $\alpha_{p}$ equal to zero. The reason for this is retention and evaporation that underlie all the amount of precipitation. As the retention is replete, $\alpha_{p}$ begins to grow gradually, tending to unity asymptotically. The value of coefficient can be approximated with a following equation:

$$
\alpha_{p}(t)=\frac{2}{\pi} \operatorname{atan} \frac{t-t_{0}}{n}
$$

where:

$t$ - current time of rainfall, 
$t_{0}$ - the parameter representing the catchment time of the watershed depends on its retention capacity and the intensity of precipitation in the initial period of its duration,

$n$ - parameter, $\alpha_{p}(t)$ curve shape indicator. It depends on the average intensity of critical rainfall [3].

\subsection{Conceptual reservoir models}

In determining the transformation of effective rainfall into surface runoff, the conceptual models have great application. Their main idea is to simplify the form of transformation as much as possible. Over the years, many such models have been created. The most popular models are reservoir models, among which the simplest is the Single Linear Reservoir Model. The concept of a linear reservoir is understood as a river drainage system that adopts a fictitious form of a retention reservoir in which changes in the retention $S(t)$ of the hydrological system are conditioned by an inflow in the form of effective precipitation $I_{E}(t)$ and outflow $Q(t)$. The dependence of these functions can be represented by the equation of continuity in the following form:

$$
I_{E}(t)-Q(t)=\frac{d S}{d t}
$$

The river catchment diagram in the form of a single linear reservoir is illustrated in the figure 4.
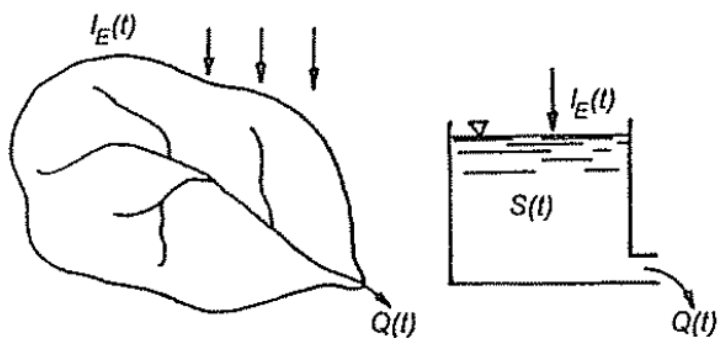

Fig. 4. The scheme of catchment as a retention reservoir [1].

Due to the lack of additional relations between the parameters of the equation (2), an additional equation determining the linear relationship between retention and outflow is introduced:

$$
S(t)=k Q(t)
$$

The equation of the recession curve is used to describe the outflow from the reservoir:

$$
Q(t)=Q_{0} e^{\frac{-\left(t-t_{0}\right)}{k}}
$$

The equation of the instantaneous unit hydrograph for outflow from the reservoir is obtained assuming that the precipitation was a fleeting impulse at the moment $t=t_{0}=0$ and the volume of water retained in the tank is unitary $S=1$. It is a mathematical model of a Single Linear Reservoir [1,5].

$$
u(t)=\frac{1}{k} e^{\frac{-t}{k}}
$$

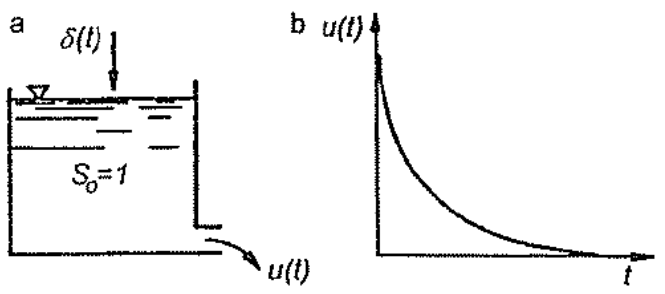

Fig. 5. Single Linear Reservoir Model (Soczyńska-red. 1997) a) reservoir, b) Reservoir outflow hydrograph [1].

Because the shape of the momentary hydrograph of the unit outflow described by equation (5) deviates from the actual shapes, the Single Linear Reservoir Model is not practically used. However, it is the basis for other models. Nash attempted to develop a linear reservoir model by using a system of $N$ reservoirs connected in series, which is shown in fig. 6 [6].

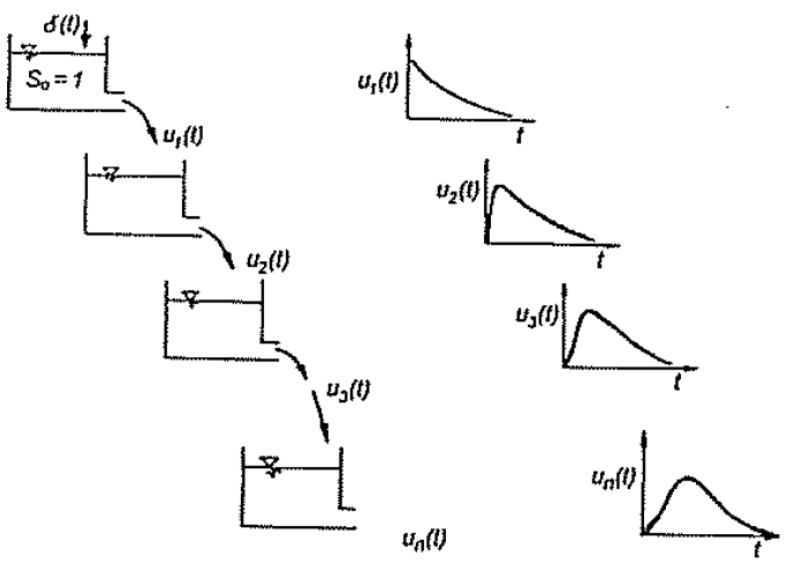

Fig. 6. Multi-reservoir Nash model.

The first of the reservoirs is analysed in the same way as the model of a single retention reservoir, and the outflow from it $u_{1}(t)$ is also an inflow to the second reservoir. Outflow from the second reservoir $u_{2}(t)$ is determined using the convolution (operating on the principle of superposition) [4]. This is due to the fact that the river basin transforms the impulses of effective precipitation in infinitesimal intervals of time $d \tau$ in the outflow distributed in time in accordance with the shape of IUH. The second reservoir works in the same way in infinitely small sections of time $d \tau$ transforms the inflow, which is the outflow form the first reservoir, into outflow. When using the convolution for the second reservoir the product $I_{d}(\tau)$ should be replaced by the product $u(\tau) d \tau$, which is the momentary inflow impulses $u(\tau)$ to the second reservoir in the time interval $d \tau$, obtained by transforming the precipitation taking place in the first reservoir. The algebraic expression $u(t-\tau)$ refers to the temporal distribution of outflow form the second reservoir for the period $t-\tau$. After passing through all subsequent $N$ reservoirs, we obtain, at the exit from the last of them, the two-parameter function of the instantaneous unit hydrograph. 


$$
u_{N}(t)=\frac{1}{(N-1) ! k}\left(\frac{t}{k}\right)^{N-1} e^{\frac{-t}{k}}
$$

Because in the case of urban basins two types of surface are distinguished, models that take this fact into account are needed. In this case, the five-parameter model proposed by Diskin, which is a development of the Nash concept, assuming two branches of cascades of reservoirs connected in parallel, can be applied. In the first branch there are $N_{l}$ linear reservoirs with retention constant $k_{1}$, while the second one is built $N_{2}$ linear reservoirs with retention constant $k_{2}$. The last- fifth, parameter $\beta$ is the indicator of division of effective rainfall between 2 cascades [7]. The function of the instantaneous unit hydrograph thus takes the form:

$$
\begin{aligned}
& u_{N}(t)=\frac{\beta}{\left(N_{1}-1\right) ! k_{1}}\left(\frac{t}{k_{1}}\right)^{N_{2}-1} e^{\frac{-t}{k_{1}}}+ \\
& \frac{1-\beta}{\left(N_{2}-1\right) ! k_{2}}\left(\frac{t}{k_{2}}\right)^{N_{2}-1} e^{\frac{-t}{k_{2}}}
\end{aligned}
$$

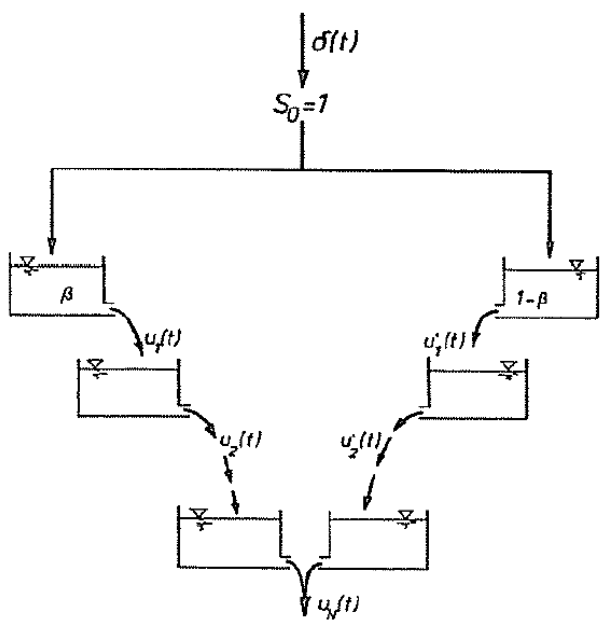

Fig. 7. The scheme of Diskin model [1].

Because of the large number of parameters of the Diskin model, which turns out to be not practical, Wackermann introduced a simplification. He assumed a fixed number of reservoirs in each cascade $N_{l}=N_{2}=2$. This resulted in a model with three parameters $k_{1}, k_{2}, \beta$ [2]. The ordinates of instantaneous unit hydrograph are obtained from the formula:

$$
u(t)=\beta u_{2}(t)+(1-\beta) u_{2}{ }^{\prime}(t)
$$

The outflow from the reservoir marked with prim means outflow from the reservoir located in the 2 nd cascade of the system.

Parameters of the model for controlled catchments are determined optimizing, while for uncontrolled catchments, empirical relationships between parameters and physiographic features of the watershed determined from the map are used. Parameters values can be calculated from the function $L / \sqrt{i}$ based on the formulas developed by Ignar [8], where $L$ is the distance from the considered cross-section to the furthest point of the catchment measured along the watercourse, and is the slope of the river on the section $L$. These functions were developed on the basis of the watersheds data with areas from 9.3 to $342.6 \mathrm{~km}^{2}$ :

$$
\begin{aligned}
& k_{1}=1.283\left(\frac{L}{\sqrt{i}}\right)^{0.159} \\
& k_{2}=0.893\left(\frac{L}{\sqrt{i}}\right)^{0.379} \\
& \beta=1.283\left(\frac{L}{\sqrt{i}}\right)^{-0.403}
\end{aligned}
$$

\section{Calculations}

\subsection{Selection of research material}

The values of precipitation and daily flows were read from the precipitation and hydrological annuals. Selection of the appropriate calculation intervals was determined by the occurrence of a flood in the river preceded by rainfall. To make this possible, the hydrographs of flows for all analysed rivers together with the hyetographs of the surrounding meteorological stations were juxtaposed. Due to this fact, we managed to select for 5 different rivers for two periods, which were analysed, in total obtaining 10 different intervals. For example, figure 8 shows the hydrograph of the Piotrkówka river flow along with the corresponding hyetograph.

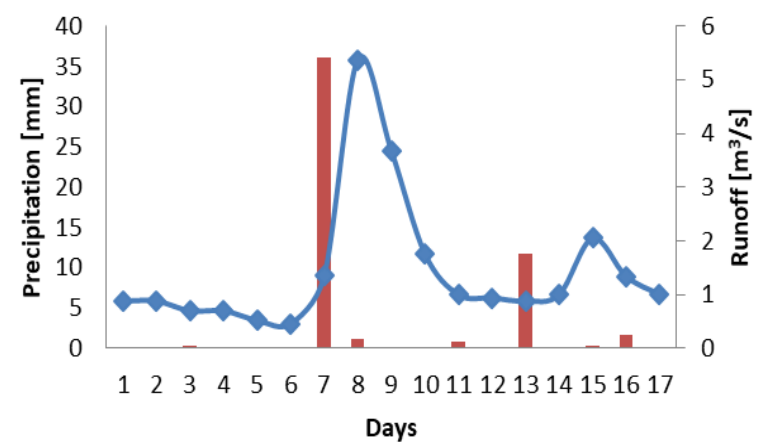

Fig. 8. Hyetograph and Hydrograph of the Piotrkówka river outflow for the analysed time interval.

\subsection{Acceptance of effective rainfall}

In the applied method of the instantaneous outflow coefficient, it is necessary to determine two independent parameters $t_{0}$ and $n$. Because of small areas of considered catchment, it is assumed with a hypothetical low risk of underestimating the value of $t_{0}=0$. Thus, it proves that the catchment will react immediately to precipitation. The slope of the outflow coefficient curve depends on the parameter $n$, which due to the lack of 
sufficient information about the basin had to be determined simultaneously with the parameters of the models used.

\subsection{Model calculation assumption}

The selection of the calculation parameters of the models and the parameter $n$ to the formula for the instantaneous outflow coefficient was carried out by multi-criteria analysis. From among the fixed set of parameter values, one set of solutions was chosen that best complying with the assumptions for each criterion. Reliable assessment of the models used requires the use of the same calculation steps. However, due to the number of parameters to identify the Diskin model, there has been a need to limit the originally assumed number of steps. Decreasing the number of calculation steps, while leaving the limit values, resulted in increasing the value of the calculation step. In tables 1-3 the limit values of the parameters used for individual models are presented along with the calculation step.

Table 1. Single Linear Reservoir Model - parameters set.

\begin{tabular}{|c|c|c|c|}
\hline Parameter & Low & High & Step \\
\hline$k$ & 0.10 & 10.10 & 1.00 \\
\hline$n$ & 0.10 & 10.10 & 1.00 \\
\hline \multicolumn{3}{|c|}{ Number of iterations } & 121 \\
\hline
\end{tabular}

Table 2. Nash Model - parameters set.

\begin{tabular}{|c|c|r|c|}
\hline & Low & High & Step \\
\hline$k$ & 0.10 & 10.10 & 1.00 \\
\hline$N$ & 1.00 & 5.00 & 0.50 \\
\hline$n$ & 0.10 & 10.10 & 1.00 \\
\hline \multicolumn{3}{|c|}{ Number of iterations } & 1089 \\
\hline
\end{tabular}

Table 3. Diskin Model - parameters set.

\begin{tabular}{|c|c|c|c|}
\hline & Low & High & Step \\
\hline$k_{I}$ & 0.10 & 10.10 & 1.00 \\
\hline$k_{2}$ & 0.10 & 10.10 & 1.00 \\
\hline$N_{I}$ & 1.00 & 5.00 & 0.50 \\
\hline$N_{2}$ & 1.00 & 5.00 & 0.50 \\
\hline$\beta$ & 0.00 & 0.50 & 0.10 \\
\hline$n$ & 0.10 & 10.10 & 1.00 \\
\hline \multicolumn{3}{|c|}{ Number of iterations } & 646866 \\
\hline
\end{tabular}

Due to the specificity of the Wackermann model, the only parameter to identify is the $n$ coefficient. Consequently, the value of $n$ will be searched in the range from 0.1 to 10.1 with a computational step of 1.0 , which gives only 11 iterations.

\subsection{Criteria for the identification of model parameters}

In the article four criteria for the selection of parameters are proposed:

- Criterion I: The best fit is the minimum difference between the actual and modelled peak values occurring at the same time;

- Criterion II: The basis for the choice of model parameters is the minimum sum of squares of differences between modelled and real values;

- Criterion III: Selection of model parameters is obtained by comparing the actual flood volume with the modelled one;

- Criterion IV: The idea of this criterion is to obtain a minimum difference in the volume of real and modelled waves, while maintaining the relative equality of the hydrographs peaks.

\subsection{Model comparison}

The Akaike information criterion was used to assess the quality of models apart from the graphical analysis of hydrographs. The basis for the Akaike criterion is not only the accuracy of the results obtained, but also the number of parameters for model identification. It may turn out that when comparing models with different number of parameters, it is not necessarily the most valuable one that best represents the actual situation. Sometimes too accurate mapping of reality while working on dependent variables makes it impossible to generalize the model. Then it may be nonsense to create such a mathematical system [3]. To get dimensionless values the Akaike criterion adapted to the needs of this paper is as follows:

$$
A I C=n \cdot \ln \frac{\sum_{i=1}^{n}\left(\frac{y_{m, i}-y_{r, i}}{\overline{y_{r}}}\right)^{2}}{n}+2 p
$$

where:

$n$ - number of analysed data,

$y_{m, i}$ - modelled data,

$y_{r, i}$ - observed data,

$\overline{y_{r}}$ - mean of the observed data.

$p$ - number of model parameters.

Moreover, to assess how well the model can predict the outcome variable the Nash-Sutcliffe coefficient was used:

$$
\mathrm{NS}=1-\frac{\sum_{i=1}^{n}\left(y_{r, i}-y_{m, i}\right)^{2}}{\sum_{i=1}^{n}\left(y_{r, i}-\overline{y_{r}}\right)^{2}}
$$

\subsection{Calculations examples}

The following figure shows the results of modelling the Nash cascade when adopting various criteria for the wave shown in Figure 9. 


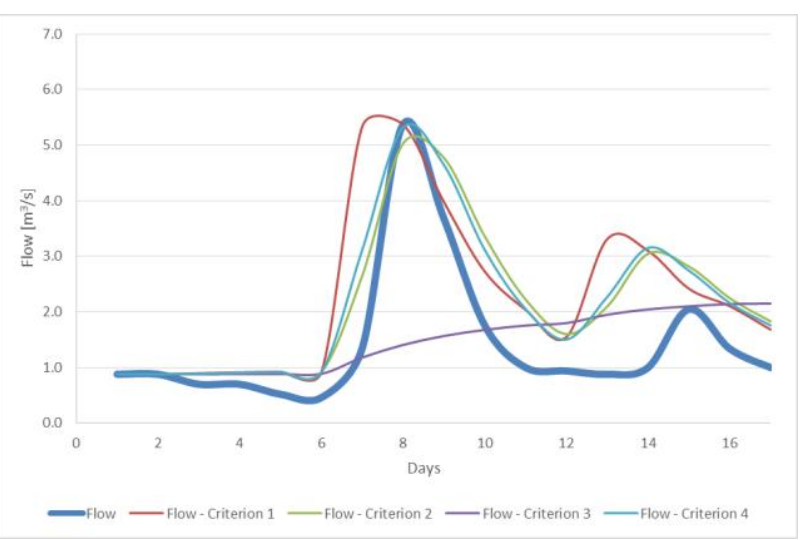

Fig. 9. Reaction of the Nash cascade depending on the criterion of model parameters identification.

The first stage of selecting the best criterion for identifying model parameters is the graphical method, on the basis of which it is stated that the highest incompatibility for the analysed case is obtained using criteria I and III. The best fit is observed through the application of criterion IV for which the Nash-Sutcliffe coefficient is 0.37 . For other models, a similar procedure was carried out, finally obtaining the best matches in the relevant models, which are shown in the figure below. Table 4 presents the values of AIC, determination and Nash-Sutcliffe coefficients.

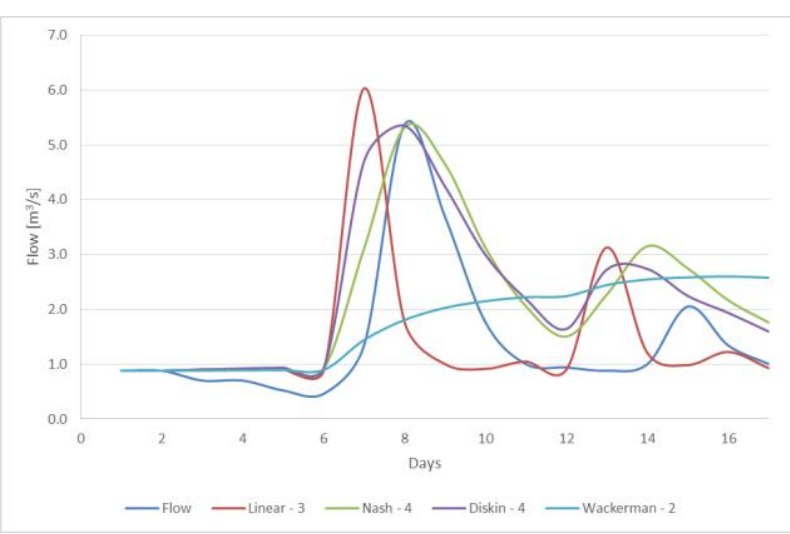

Fig. 10. Comparison of conceptual models.

Table 4. Comparison of coefficients values.

\begin{tabular}{|c|c|c|c|c|}
\hline Model & $\begin{array}{c}\text { Single Linear } \\
\text { Reservoir } \\
\text { Model }\end{array}$ & $\begin{array}{c}\text { Nash } \\
\text { Model }\end{array}$ & $\begin{array}{c}\text { Diskin } \\
\text { Model }\end{array}$ & $\begin{array}{c}\text { Wackermann } \\
\text { Model }\end{array}$ \\
\hline $\begin{array}{c}\text { Best } \\
\text { fitting } \\
\text { criterion }\end{array}$ & III & IV & IV & II \\
\hline AIC & 9.079 & $\mathbf{- 8 . 0 4 1}$ & 3.771 & -2.383 \\
\hline NS & -0.930 & $\mathbf{0 . 3 7 3}$ & 0.118 & -0.106 \\
\hline
\end{tabular}

According to the applied criteria for assessing the quality of models, the Nash model turns out to be the most effective, which is reflected in the visual method of graphical evaluation of hydrographs. An analogous analysis was made for the remaining research periods

\subsection{Calculations results}

The table 5 presents the aggregate results of the model quality assessment based on the Nash-Sutcliffe coefficient value, the Akaike information criterion, and a summary of the best-matching criteria for parameter identification.

Table 5. Calculations results.

\begin{tabular}{|c|c|c|c|c|c|}
\hline Case & Model & $\begin{array}{c}\text { Single } \\
\text { Linear } \\
\text { Reservoir }\end{array}$ & Nash & Diskin & $\begin{array}{c}\text { Wacker } \\
\text { mann }\end{array}$ \\
\hline \multirow{3}{*}{1} & criterion & III & IV & IV & II \\
\hline & AIC & 23.379 & 36.181 & 42.046 & 25.963 \\
\hline & NS & -1.040 & -2.851 & -2.821 & -1.671 \\
\hline \multirow{3}{*}{2} & criterion & II & IV & IV & III \\
\hline & AIC & -7.037 & -11.021 & 4.316 & -6.358 \\
\hline & NS & 0.794 & 0.894 & 0.701 & 0.723 \\
\hline \multirow{3}{*}{3} & criterion & II & I/II & $\mathrm{I} / \mathrm{II}$ & - \\
\hline & AIC & 15.112 & 8.943 & 16.227 & \\
\hline & NS & 0.369 & 0.664 & 0.629 & \\
\hline \multirow{3}{*}{4} & criterion & II & IV & IV & II \\
\hline & AIC & -8.336 & -4.586 & 4.823 & -3.101 \\
\hline & NS & 0.778 & 0.746 & 0.669 & 0.612 \\
\hline \multirow{3}{*}{5} & criterion & IV & IV & IV & III \\
\hline & AIC & -3.515 & -4.353 & 1.009 & -10.190 \\
\hline & NS & 0.770 & 0.857 & 0.871 & 0.895 \\
\hline \multirow{3}{*}{6} & criterion & II & I & IV & II/III \\
\hline & AIC & 68.760 & 3.817 & -56.931 & 26.765 \\
\hline & NS & -41.582 & 0.170 & 0.984 & -3.050 \\
\hline \multirow{3}{*}{7} & criterion & III & I & $\mathrm{I} / \mathrm{II}$ & I/II/III \\
\hline & AIC & -12.380 & -3.675 & -4.380 & -7.675 \\
\hline & NS & 0.851 & 0.740 & 0.851 & 0.740 \\
\hline \multirow{3}{*}{8} & criterion & III & I & I/III & I/II/III \\
\hline & AIC & 4.855 & 3.598 & 9.558 & 0.151 \\
\hline & NS & 0.559 & 0.672 & 0.673 & 0.655 \\
\hline \multirow{3}{*}{9} & criterion & I & I & $\mathrm{I} / \mathrm{IV}$ & I/II/III \\
\hline & AIC & -17.080 & -14.522 & -54.842 & 24.799 \\
\hline & NS & 0.815 & 0.806 & 0.996 & -6.182 \\
\hline \multirow{3}{*}{10} & criterion & II & I & I & I/II/III \\
\hline & AIC & -12.351 & -60.884 & -54.884 & 22.653 \\
\hline & NS & 0.625 & 0.981 & 0.981 & -2.304 \\
\hline
\end{tabular}

The most accurate responses were obtained using the criteria determining the simultaneous occurrence of wave peaks, i.e. criterion no. I and criterion IV. The best criterion used to identify the parameters turned out to be the original criterion of the difference in volume of overlapping peaks, i.e. criterion IV. In each of the 
analysed cases, for which this criterion could be applied, the best fit of the hydrograms was obtained. Criterion number III brought the expected results almost exclusively in the case of a single linear reservoir.

Analysing the average values of efficiency coefficients and usability of models, it turns out that the best model is the conceptual model of Diskin. For this model, the highest average value of coefficient NS $=0.45$ and the lowest AIC value -9.31 were obtained. This conclusion, however, is not fully confirmed in the situation when we consider each case of the analysed flooding separately. Most often, the lowest AIC value was received for the Single Linear Reservoir Model and Nash Model. The values of the applied coefficients verifying the quality of models do not always coincide with the visual assessment of matching the received hydrographs, and yet the graphic method has the highest weight.

\section{Conclusions}

The study examined the effectiveness and usability of four conceptual reservoir models: Single Linear Reservoir, Nash, Diskin and Wackermann. The first problem has already been encountered in the determination of effective precipitation, as no method has been created so far to accurately determine the amount of effective precipitation. The method of instantaneous outflow coefficient was used, in which the parameter $n$, due to the lack of sufficient information, was determined simultaneously with the parameters of the models. Logical reasoning suggests that the Diskin model is the most effective of the analysed reservoir models. With proper selection of its parameters either a single reservoir or a single cascade or a two-cascade scheme can be obtained. This is reflected in the results of this work. The highest mean value of NS coefficient was obtained for the Diskin model. Unfortunately, the model contains as many as 5 parameters, which reduces its usability and significantly extends the calculation process. The applied reduction of the calculation steps of the model resulted in lower accuracy of calculations, which could be noted in some of the analysed cases. Good matching of the real and modelled runoffs was obtained using Nash cascade. Its accuracy did not differ significantly from Diskin model, and due to the twoparameter concept, it is very useful. Graphically, the Wackermann model performed the worst, which was sometimes not confirmed by the Nash-Sutcliffe coefficient. Because the visual assessment of the modelled hydrographs is the most significant verification criterion, it can be concluded that the verification factors used do not allow to unambiguously assess the accuracy of matching modelled hydrographs. In addition, it was noticed that the obtained values of the model and effective precipitation parameters, and thus - the accuracy of matching the modelled hydrographs, depend on the adopted criterion of parameter identification. The most accurate reflections were obtained for the criteria determining the time of occurrence and the size of the peak of the wave. The most effective turned out to be the original criterion of the difference of the volumes of the overlapping peaks, i.e. criterion IV.

\section{References}

1. A. Byczkowski, Hydrologia, vol. 2 (Wydawnictwo SGGW, 1990)

2. M. Ozga-Zielińska, J. Brzeziński, Hydrologia stosowana (Wydawnictwo naukowe PWN, 1997)

3. U. Soczyńska, Podstawy hydrologii dynamicznej (Wydawnictwo WUW, 1990)

4. J. Kindler, Matematyczne modele zlewni (Wydawnictwo ZN, 1974)

5. J.T. Pedersen, J.C. Peter, O.J. Helweg, US Army Corps for Engineers (1980)

6. V. P. Singh, Studies on rainfall-runoff modelling (Water Resources Research Institute, 1977)

7. M.H. Diskin, Estimation of urbanization effects by a parallel cascades model, Proceedings of Symposium on the influence of man on the hydrological regime with special reference to representative and experimental basins (Helsinki, IAHS-AIHS, 37, June, 1980)

8. S. Ignar, Metodyka obliczania przepływów wezbraniowych $w$ zlewniach nieobserwowanych (Wydawnictwo SGGW, 1993) 